\title{
Using DI Flashcards with a Count-By Series Procedure with a Fourth Grade Student with ADHD and Learning Issues in a Resource Room Setting Math Facts with an Evaluation of Generalization to New Math Facts

\author{
Christy Wilson $^{1}$, T. F. McLaughlin ${ }^{2} \&$ Andrea Bennett $^{1}$ \\ ${ }^{1}$ Central Valley School District \#359, Spokane Valley, WA, USA \\ ${ }^{2}$ Department of Special Education, Gonzaga University, Spokane, WA, 99258-0025, USA \\ Correspondence: T. F. McLaughlin, Department of Special Education, Conzaga University, Northern Spokane, \\ WA 99258-0025, USA. Tel: 1-509 -313-3508. E-mail: mclaughlin@gonzaga.edu
}

Received: January 22, 2016

Accepted: January 29, 2016 Online Published: February 26, 2016

doi:10.20849/aes.v1i1.6

URL: http://dx.doi.org/10.20849/aes.v1i1.6

\begin{abstract}
DI flashcards have been proven be improve student performance in a wide range of subject matter-areas. Students with memory issues may well benefit from being taught with DI flashcards. Employing a count-by series has been employed by classroom teachers to teach multiplication. Count-bys can provide students an easy transition from addition to multiplication. This project implemented DI flashcards with a count by series to improve the performance of a single elementary school student having difficulty in math. These two procedures were evaluated in an ABABCB single case design. The results indicated that our participant's performance increased when these two procedures were combined. Finally generalization was carried out with new math facts. When DI flashcards and the count by series charts were again employed with his new math facts, his performance quickly increased. Suggestions for future research employing DI flashcards and generalization of treatment outcomes were also provided.
\end{abstract}

Keywords: DI flashcards, county by series, single case research, ADHD, LD, memory issues, classroom research, case study

\section{Introduction}

Factors that moderate the slower computational performance of youth do not appear to be related to cognitive ability as much as to specific cognitive style variable (inattention, disorganization), often associated with youth who have LD, ADD, and ADHD (Barkley, 2014; Zentell \& Ferkis, 1993). Attention-Deficit-Hyperactivity-Disorder (ADHD) belongs to the most common neuro-behavioral childhood disorders with a world-wide prevalence of 5.3\% (Baudry, 2013). Also ADHD is characterized by two core symptoms that may co-occur: inattention and over-activity-impulsiveness at home as well as in school environment (Barkley, 2014; Heward, 2013). Several malleable and non-malleable environmental factors have been suggested to increase the risk for ADHD. Among them, time spent in front of the television single-parent headed households, parental education, maternal age at birth, and maternal smoking (Barkley, 2014; Baudry, 2013; Bylsma \& Shannon, 2003, 2005; Bylsma, Shannon, Bergeson, \& Heuschel, 2005). Less is known about links between ADHD and mathematics disability, despite evidence that comorbidity rates between ADHD and mathematics disability may be similar to those between ADHD and reading disability (Capano, Minden, Chen, Schacher, \& Ickowicz, 2008). Because ADHD and mathematics disability are heritable (Kovas, Haworth, Petrill, \& Plomin, 2007; Willcutt et al., 2010) their comorbidity might be due to shared genetic risk factors. However, genetically sensitive research examining links between ADHD and mathematics disability remains relatively sparse (Greven, Kovas, Willcutt, Petrill, \& Plomin, 2014).

There are about $5 \%$ to $8 \%$ of students who have memory or other cognitive deficits that interfere with their ability to acquire, apply, or master mathematical concepts and skills. By employing evidenced based procedures such as DI flashcards may help students to overcome these challenges (Geary, 2004; Thomas, McLaughlin, \& Derby, 2015). Students without multiplication fact fluency spend more time determining routine answers and less time on more meaningful applications (Silbert, Carnine, \& Stein, 1981; Wallace \& Gurganus, 2005), while 
students who know their facts build on these fundamental concepts, ultimately benefiting their later mathematical development.

The comprehension of mathematics demands practice of the subject and realizing the patterns of the subject matter in math (Silbert et al., 1981; Wallace \& Gurganus, 2005). Out of the 5 to 8 percent of children who may have specific mathematic disabilities (L. Fuchs \& Fuchs, 2003) the nature of these disabilities varies considerably among children. This means that quick recall of previously learned mathematics facts may be related to a student's working memory, semantic retrieval, and ability to inhibit irrelevant information (Geary, 2003; Swanson, Carson, \& Lee, 1996; Swanson, Harris, \& Graham, 2013).

Given the importance knowing one's basic math facts for multiplication, educators have been employing a wide range of activities to teach such skills to their students. Studies using constant time-delay techniques with a count-by series, have demonstrated that students with mathematics disabilities can develop fluency with facts and maintain fluency over time (Haring \& Eaton, 1978; Koscinski \& Hoy, 1993; Shapiro, 2011). Duvall, McLaughlin, and Cooke-Sederstrom, (2003) employed count-by-series (skip counting) to improve the math fact performance of middle school students with learning disabilities. Unfortunately, only two of the three students showed marked improvement. The count-by series strategy can be used as a visual cue for students who are having difficulty memorizing multiplication facts, and as a concrete way of learning multiplication facts that can be slowly faded out once the learning has been mastered. The count-by series could be used as a self-initiated reminder by students to independently use as a way to improve and master their math facts. This strategy provides students a way of self-checking their own mental math of multiplication fact memorization. The count-by series (skip counting) can be employed with everyday math to make it easier to learn and give students the answers they need to acquire more complex basic skills.

Another intervention initially developed by Silbert et al., (1981) to assist students in learning their math facts has been called Direct Instruction (DI) flashcards. DI flashcards have been found to be an efficient and data based way to teach math facts to a wide range of students (Lund, McLaughlin, Derby, \& Everson, 2012; Thomas, McLaughlin, \& Derby, 2015). Briefly, DI flashcards can be used as a tool determining which facts need to taught, which facts the student already know, and when should a fact be defined as learned and a new fact added (Silbert et al., 1981; Thomas et al., 2015). A student is given a pretest to determine which facts are known and those that are not known. Next these facts are arranged in different sets or stacks. Typically these stacks can contain from 6 to 15 facts. Carnine et al. suggested that a ratio of known to unknown facts should be large. In this way, DI flashcards can help learning of multiplication facts by only presenting a few new facts at a time. This also permits the introduction of additional facts once a fact or set of facts has been mastered. Finally, model, lead, and test error correction is a very important aspect when teaching a skill using DI flashcards. Basically, this involves the teacher or tutor reading the fact and the correct solution. Next, the teacher and student read the fact and its solution together. Finally, the student is required to state the fact and its solution. If the child is correct, then a new fact is presented. If the student makes an error, the error correction procedure is repeated. The may take from one to a several trials for the student to state the fact and its correct solution.

There has been a great deal of research supporting the use of DI flashcards for students with learning disabilities (Brinegar, McLaughlin, \& Love, 2016; Chandler, McLaughlin, Derby, \& Waco, 2012; Erbey, McLaughlin, Derby, \& Everson, 2012; Lund et al., 2012; Mann, McLaughlin, Derby, Williams, \& Everson, 2013; Pfaff, McLaughlin, Neyman, \& Everson, 2013; Skarr et al., 2014), students with behavior disorders (Brasch, Williams, \& McLaughlin, 2008; Pierce, McLaughlin, Neyman, \& King, 2012; Treacy, McLaughlin, Derby, \& Schlettert, 2012), students with developmental delays (Ruwe, McLaughlin, Derby, \& Johnson, 2011; Mangundayo, McLaughlin, Derby, Williams, \& Toone, 2013); or intellectual disabilities (Crowley, McLaughlin, \& Kahn, 2013). DI flashcards have been employed in special as well as in general education classrooms. DI flashcards have also been shown to be effective in private school classrooms (Rivera, Heric, Williams, McLaughlin \& Johnson, 2014). Finally, DI flashcards have been employed to teach skills ranging from teaching sight words (Kaufman, McLaughlin, Derby, \& Waco, 2011), improving letter recognition (Mangundayo et al., 2013), or mastering letter sounds (Lapke \& McLaughlin, 2015).

The count-by-series strategy can be used as a covert cue for students who are having difficulty memorizing multiplication fact. Count bys can also be viewed as a concrete way of learning multiplication facts. The use of count bys could be slowly faded once the learning has been mastered. This strategy provides students a way of self-checking their own mental math of multiplication fact memorization. The count-by series (skip counting) can be related to real world math to make it easier to learn and give students the answers they need to acquire more complex basic skills. 
According to Stokes and Baer (1977) generalization of treatment effects continues to be a very important outcome of behavioral research. Generalization should be an active process and classroom personnel should program and assess their interventions effects over time. Since, generalization to treatment effects remains a very critical outcome, we attempted to assess generalization after experimental control had been established using DI flashcards and a count-by-series with a set of new facts. We did not find generalization to a new group of math facts. Therefore, we employed our previous procedures to the new problem set to assist in the teaching these new math facts.

The purpose of the present case report was to implement DI flashcards and count-by series to assist a single student in multiplication. We wanted to increase his skills in a logical progression (Steedly, Dragoo, Arefeh, \& Luke, 2008). A final purpose was to assess generalization to treatment effects after our participant had reached during second application of DI flashcards and a count by series. Generalization was assessed with another problem class the times 6 's.

\section{Method}

\subsection{Participant (Subject) Characteristics}

The participant was a 9-year-old boy attending a public school in the Pacific Northwest. Our participant had no other siblings living in the home. He had a large number of unexcused absences and had almost met the criteria for the Becca Bill in the State of Washington (Bylsma \& Shannon, 2003). Our participant had been assessed by the school's multi-disciplinary team. This assessment outcome led to 900 minutes of instruction per week in a resource room classroom in reading, written language, and math. The first author met with the participant's resource teacher and they both came to an agreement that he needed help with his multiplication facts. The participant has been trying to do multiplication problems at his grade level but has been unsuccessful so far. The data collection and instruction took place in the participant's resource room at a table only used by the first author and participant. Also, there were other children in the resource room, and at least two other teachers as well when instruction took place.

\subsection{Measures and Covariates}

The dependent variable was the number correct of multiplication facts using DI Flashcards and the count-by-series for fours. The first author graphed the number of correct flashcards answered correctly in each of the flashcard sessions. Data were collected and put into a reversal design graph by the first author. The independent variable (intervention) was a DI Flashcard procedure and count-by-series used to help with memorization of multiplication facts. During each session the first author would present the participant with flashcards ranging from $4 \times 0$ to $4 \times 9$ to answer in a random order. If the participant could answer the flashcards on his own correctly, and not exceed 10 seconds per card, then the first author would deliver positive praise. The first author also had a reward for the student to receive at the end of the whole project.

If the participant was not able to answer flashcards correctly on his own in the designated time frame the first author would then help him to utilize his count-by-series chart while answering to the flashcards presented. Before the start of the intervention the first author first modeled how to look at the flashcard presented and then use the count-by-series to help him answer correctly and quickly. A wrong answer to a flashcard was only marked incorrect on the data sheet once the participant gave a full response in the allotted time per card.

The second measure was the number of non-overlapping data points (Scruggs \& Mastropieri, 2001; 2013; Scruggs, Mastropieri, \& Casto, 1987). This has been suggested as a general measure of effectiveness with single case research designs. The number of data points in intervention are compared to the number of data points in intervention in terms of the percent of data points that are not overlapping. This is then employed to assess the effectiveness of the intervention (Scruggs et al., 1987).

\subsection{Experimental Manipulations}

An ABABCD single case research design (Kazdin, 2011; McLaughlin, 1983) was employed to evaluate and assess the effectiveness of DI flashcards with count bys. Also, the final two conditions examined the generalization of treatment effects to another problem class.

Baseline 1. During Baseline 1 the participant was shown 10 flashcards. He has allowed no more than 10 seconds to provide an oral answer to the math fact presented. Baseline data were gathered on two different school days with three sessions being conducted each day. No feedback or help was provided during baseline for our participant.

DI flashcards + count-by-series procedure 1. During DI flashcards, the first author presented the participant with 
the same 4's multiplication flashcards at random. Also, the count by series was introduced at this time. The teacher modeled how the county by series could help him answer the math facts correctly. In addition, when an error took place, a "model-lead-test" procedure (Bulkley, McLaughlin, Neyman, \& Carosella, 2012; Marchand-Martella, Slocum, \& Martella, 2004) was employed with the participant. In addition, he was taught to employ his count by series chart using model, lead, and test. This condition was in effect for four different school days for a total of eight sessions.

Baseline 2. In baseline 2 the first author still presented the participant with the same consecutive 4's flashcards. However, we removed his count-by-series chart and the model, lead, and test error correction procedure.. This condition was in effect for two school days totaling four sessions.

DI flashcards + count-by-series procedure 2. This time the first author added the count-by-series to the DI flashcard procedures. The first author also provided the participant a quick reminder of how to use the count-by-series. During this second intervention our participant was provided the same nine 4's flashcards randomly. The first author also went over how to use the count-by-series at the beginning of each session. This condition was in effect for five sessions across three different school days.

Generalization to $x 6$ 's. To assess generalization to the $\mathrm{x} 6$ 's, the count by series procedure and error correction were again removed. Our participant was not able to employ the count by series procedures and chart. In addition, the first author did not provide error correction when the DI flashcards were presented to the participant. This was in effect for three school days and four sessions.

DI flashcards + county-by-series procedure $x 6$ 's. This was a reintroduction of the DI flashcards and the count by series procedure for the generalization facts $\mathrm{x} 6$ 's. It was in effect for four schools days and four sessions.

\section{Results}

The number of correct answers our participant is displayed in Figure 1. The mean number of correct multiplication problems correct answered during baseline 1 was 3.5 (range 3 to 5 correct). When DI flashcards + county bys were in effect, the mean number of correct flashcards answered increased to 9.75 with a range of 9 to 10 correct.

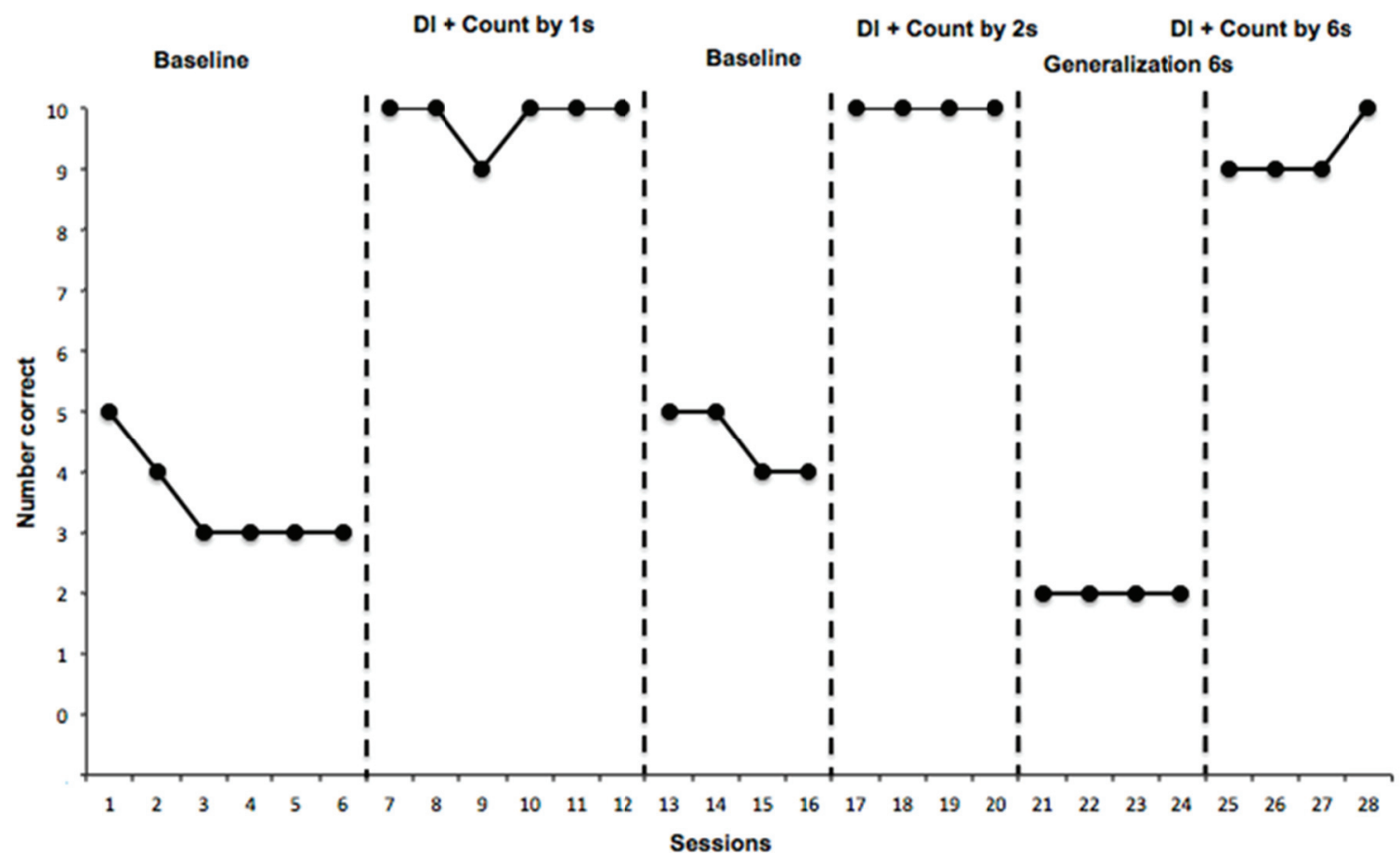

Figure 1. The number correct for each baseline and DI flashcards by count by series chart, generalization to x6's and finally DI flashcards and count by series chart $\mathrm{x} 6$ 
The return to baseline (Baseline 2 resulted in a sharp decrease in our participant's performance $(M=4.75$; range 4 to 5 correct) with his $\mathrm{x} 4$ 's. A replication of DI flashcards and the count by series chart produced an increase as well as mastery of his $\mathrm{x} 4$ math facts answered correctly $(M=10)$. When generalization was assed to a new set of math facts (x6's), our participant's performance was low $(M=2.0)$, and we observed little generalization to his $\mathrm{x}$ 6's. However, when we again employed DI flashcards and count-by-series charts, his performance quickly improved for his x6's $(M=9.25$; range 9 to 10 correct $)$.

\subsection{Statistics and Data Analysis}

The percent of non-overlapping data points between baseline 1 and DI flashcards + count by series 1 was $100 \%$. The number of non-overlapping data points between baseline 2 and DI flashcards + count by series 2 was also $100 \%$. The percent of non-overlapping data points between generalization x6's and employing DI flashcards + count by series x6's was $100 \%$. The overall outcomes indicated that employing DI flashcards + count by series was a highly effective procedure.

\section{Discussion}

DI flashcards with count-by-series procedure and chart generated some positive effects for our participant. His performance was low both baseline conditions. Our participant increased correct answers when DI flashcards and a count by series were employed. The first author also noted that once our participant used the count-by-series procedure, he needed less prompting ad assistance from the first author. The combination of the increase in correct answers and the decrease in prompting seemed to have a very positive effect on the participant's motivation to answer correctly rather than hurry through and answer incorrectly just to get done with the flashcards.

The classroom staff indicated that once the participant started using the count-by-series procedure correctly a reduction for his complaining and unfocused behavior decreased as well. Our participant answered flashcards with more motivation during intervention rather than baseline, because he felt confident in getting the correct answers by himself. The count-by series Procedure gave the participant a useful tool for answering multiplication questions quickly and on his own. The participant had no problems at all working with the first author on this project except for making it to school every day, so the first author added a reward to be given to the student at the end of the project if he finished the whole project. The reward was a positive reinforcer to motivate the participant to come to school on the days he was supposed to meet with the first author. Once the reward was in place as part of the project the student made it to school on those specified days. His motivation to answer flashcards correctly and independently also aided the participant in learning the count-by series way quickly because he indicated that he did not want to have to depend on the first author for help.

The present outcomes using DI flashcards with model, lead, and test with a count by series procedure replicates a great deal of our research in teaching math facts (Erbey et al., 2012; Lund et al., 2012; Mann et al., 2012; Skarr et al., 2013). It is also consistent with our use of error correction in other academic areas (Bechtoldt et al., 2013).

A limitation in the present case report was the small number of sessions that were able to carry out. Also, the number of school days that the first author could come to the classroom and work with the participant was variable. We felt it could have easily went another 6 months to really help the participant become quite competent with our procedures and use them at school but in daily life.. Another definite weakness was not necessarily of the project itself, but of the participant itself. At times he lacked motivation to even attend school. We developed a reward system for attendance. The reward employed was going to the resource room. This reward system helped tremendously with the attendance of our participant. Both the classroom staff was well as others in the school were impressed with our choice of reward because of the fact that it made the participant accountable for coming to school as well as being paired with his performance in math.

DI flashcards and the count-by series could be readily used educators in other mathematical computation. Our work and those of others have found that flashcards can be implemented in almost any setting and teach specific skills quickly and easily (Erbey et al., 2012; Lund et al., 2012; Skarr et al., 2013). As for the count-by series; skip counting was important in the development of fluency in calculation, number sense and as the basis of multiplication and division. Duvall et al., (2006) also found this to be the case.

The participant's resource room teacher said our participant and her student will be required to continue to use these procedure in the resource room during math. Hopefully, the participant will keep using the count-by series procedure when working with other multiplication facts. The only adjustment to be made would be to leave the participant with a small laminated card of each count-by series Count-by series from 1-12. This way it could be easily pulled out and used by the participant anytime that he needed it. After that the count-by series card could 
be faded out as he learns more of the multiplication facts from 1 to 12 .

The count-by series procedure can be part of many aspects of teaching math facts. One of the first key math concepts taught to students as early as kindergarten is counting by 2's, 4's, 10's and so on. When a student does not get the chance to fully grasp this concept at the right early age it can have devastating effects on their upper elementary math learning where multiplication is depended on heavily to master most math skills. Children who struggle with multiplication fact memorization can benefit from the use of DI flashcards and the use of the count-by series to help them with their fact memorization.

\section{Acknowledgments}

This research was completed in partial fulfillment for the requirements for an Endorsement in Special Education from the Department of Special Education at Gonzaga University and the Office of the Superintendent of Public Instruction in Olympia, WA.

Ms. Wilson is currently a Masters of Initial Teaching student in the Department of Special Education at Gonzaga University.

\section{References}

Barkley, R. A. (2014). ADHD: A handbook for diagnosis and treatment. New York, NY: Guilford Press.

Baudry, M. (2013). Children with ADHD symptoms have a higher risk for reading, spelling, and math difficulties in the GINIplus and LISAplus cohort studies. PLOS ONE, 8.

Bechtoldt, S., McLaughlin, T. F., Derby, K. M., \& Blecher, J. (2014). The effects of direct instruction flashcards and a model, lead, and test procedure on letter recognition for three preschool students with developmental disabilities. Journal on Developmental Disabilities, 20(1), 5-15.

Brasch, T. L., Williams, R. L., \& McLaughlin, T. F. (2008). The effects of a direct instruction flashcard system on multiplication fact mastery by two high school students with ADHD and ODD. Child \& Family Behavior Therapy, 30(1), 51-59. http://dx.doi.org/10.1300/J019v30n01_04

Brinegar, K., McLaughlin, T. F., \& Love, D. (2016). A replication of the use of direct instruction flashcards to teach a fourth grade student with learning disabilities math facts: A case report. International Journal of Basic and Applied Science, 4(3), 9-17. Retrieved from http://insikapub.com/Vol-04/No-03/02IJBAS(4)(3).pdf

Bulkley, L., McLaughlin, T. F., Neyman, J., \& Carosella, M. (2012). The effects of a model, lead, and test procedure to teach letter name and sound identification to elementary school students with learning disabilities. Electronic International Journal of Educational Research, 3(4), 50-64. Retrieved from http://www.e-ijer.com/

Bylsma, P., \& Shannon, G. (2003). Helping students finish school: Why students drop out and how to help them graduate. Olympia, WA: Office of Superintendent of Public. Retrieved from: http://www.k12.wa.us/research/pubdocs/dropoutreport2006.pdf

Bylsma, P., \& Shannon, G. (2005). Promising programs and practices for dropout prevention: Report to the legislature. Olympia, WA: Office of Superintendent of Public Instruction. Retrieved from http://www.k12.wa.us/research/pubdocs/PromisingProgramsandPractices.pdf

Bylsma, P., Shannon, G., Bergeson, T., \& Heuschel, M. (2005). Promising programs and practices for dropout prevention report to the legislature. Olympia, WA: Office of Superintendent of Public Instruction. Retrieved from: http://www.k12.wa.us/research/default.aspx

Capano, L., Minden, D., Chen, S. X., Schacher, R. J., Ickowicz, A. (2008). Mathematical learning disorder in school-age children with attention-deficit-hyperactivity-disorder. Canadian Journal of Psychiatry, 53, 392-399.

Chandler, A., McLaughlin, T. F., Neyman, J., \& Rinaldi, L. (2012). The differential effects of direct instruction flashcards with and without a shorter math racetrack to teach numeral identification to preschoolers: A failure to replicate. Academic Research International, 2(3), 308-313. Retrieved from $\mathrm{http}: / / 174.36 .46 .112 / \sim$ savaporg/journals/issue.htm/

Cravalho, C. J., McLaughlin, T. F., Derby, K. M., \& Waco, T. (2014). The effects of direct instruction flashcards on math performance with measures of generalization across elementary students with learning disabilities and autism spectrum disorder. International Journal of Basic and Applied Science, 2(4), 16-31. Retrieved from http://www.insikapub.com/ 
Crowley, K., McLaughlin, T. F., \& Kahn, R. (2013). The effects of direct instruction flashcards, reading racetracks on sight word skills for two elementary students with autism. Journal of Developmental and Physical Disabilities, 26, 297-311. http://dx.doi.org/10.1007/s10882-012-9307-z

Duvall, T., McLaughlin, T. F., \& Cooke-Sederstrom, G. (2003). The differential effects of skip counting and previewing on the accuracy and fluency of math facts with middle school students with learning disabilities. International Journal of Special Education, 18(1), 1-7. Retrieved from http://www.internationaljournalofspecialeducation.com

Geary, D. C (2004). Mathematics and learning disabilities. Journal of Learning Disabilities, 37, 4-15. http://dx.doi.org/10.1177/00222194040370010201

Greven, C., Kovas, Y., Willcutt, E. G., Petrill, S. A., \& Plumin, R. (2014). Evidence for shared Genetic risk between ADHD symptoms and reduced mathematics ability: A twin study. Journal of Child Psychology and Psychiatry, 55, 39-48. http://dx.doi.org/10.1111/jcpp.12090

Grunke, M., \& Stegemann, K. C. (2014). Using count-bys to promote multiplication fact acquisition for a student with mild cognitive delays: A case report. Journal of Contextual Behavioral Science, 3, 65-68.

Haring, N. G., \& Eaton, M. D. (1978). Systematic instructional procedures: an instructional hierarchy. In N. C. Haring, T. C. Lovitt, M. D. Eaton, \& C. L. Hansen (Eds.), The fourth R: Research in the classroom (pp. 23-40). Columbus, OH: Charles E. Merrill.

Heward, W. L. (2013). Teaching exceptional children: An introduction to special education. Upper Saddle River, NJ: Prentice-Hall/Pearson.

Kaufman, L., McLaughlin, T. F., Derby, K. M., \& Waco, T. (2011). Employing reading racetracks and DI flashcards with and without cover, copy, and compare and rewards to teach of sight words to three students with learning disabilities in reading. Educational Research Quarterly, 34, 24-44.

Kazdin, A. E. (2011). Single case research designs: Methods for clinical and applied settings. New York: Oxford University Press.

Koscinski, S. T., \& Hoy, C. (1993). Teaching multiplication facts to students with learning disabilities: The promise of constant time-delay procedures. Learning Disabilities Research and Practice, 8, 260-263.

Kovas, Y., Haworth, C. M. A., Petrill, S. A., \& Plomin, R. (2007). Overlap and specificity of Genetic and environmental influences on mathematics and reading disability in 10 year-old wins. Journal of Child Psychology and Psychiatry, 48, 914-922. http://dx.doi.org/10.1111/j.1469-7610.2007.01748x

Lapke, M., \& McLaughlin, T. F. (2015). The effects of direct instruction flashcards to increase number recognition for a five-year-old general education ell student. World Wide Journal of Multidisciplinary Research and Development, 1(6), 6-11. Retrieved from http://wwjmrd.com/vol\%201/issue\%206/issue\%206.html

LeBrun, C., Jones, S., Neyman, J., McLaughlin, T. F., \& Schuler, H. (2014). The effects of a modified direct instruction flashcard system on a 14 year-old-student with learning behavioral issues enrolled in a behavior intervention classroom. International Journal of Undergraduate Education and Creative Activities, 6, 1-9. Retrieved from http://commons.pacificu.edu/ijurca/ http://dx.doi.org/10.7710/2168-0620.1033

Lerner, J. (2001) Learning disabilities theories, diagnosis, and teaching strategies (7th ed.). Boston: Houghton Mifflin Co.

Lund, K., McLaughlin, T. F., Neyman, J., \& Everson, M. (2012). The effects of DI flashcards and math racetrack on multiplication facts for two elementary students with learning disabilities. Journal of Special Education Apprenticeship, 1(1), 1-15. http://josea.info/index.php?page=vollno1

Mann, Z., McLaughlin, T. F., Williams, R. L., Derby, K. M., \& Everson, M. (2012). The effects of direct instruction flashcards and rewards with math facts at school and in the home: acquisition and maintenance. Journal of Special Education Apprenticeship, 1(2). Retrieved from http://josea.info/index.php?page=archives

McLaughlin, T. F. (1983). An examination and evaluation of single subject designs used in behavior analysis research in school settings. Educational Research Quarterly, 7, 35-42.

Marchand-Martella, N., Slocum, T., \& Martella, R. (2004). An introduction to direct instruction. Boston, MA: Allyn \& Bacon. 
Pfaff, E., McLaughlin, T. F., Neyman, J., \& Everson, M. (2013). The effects of direct instruction flashcards with math racetrack with addition facts for an elementary school student with ADHD. International Journal of Basic and Applied Science, 2(1), 124-130. Retrieved from: http://www.insikapub.com/

Pierce, K., McLaughlin, T. F., Neyman, J., \& King, K. (2012). The gradual and differential effects of direct instruction flashcards with and without a DRH contingency on basic multiplication facts for two students with severe behaviors disorders. i-manager's Journal on Educational Psychology, 6(2), 35-44. Retrieved from: http://www.imanagerpublications.com/Archives.aspx

Rivera, G., Heric, K., Williams, R. L., McLaughlin, T. F., \& Johnson, G. (2014). The use of direct instruction multiplication flashcard and a modified math racetrack procedures on mastery of multiplication facts for an at-risk $6^{\text {th }}$ grade girl. The Open Journal of Education, 7, 7-11. Retrieved from http://www.benthamscience.com/open/toecij/ http://dx.doi.org/10.2174/1874920801407010007

Ruwe, K., McLaughlin, T. F., Derby, K. M., \& Johnson, K. (2011). The multiple effects of direct instruction flashcards on sight word acquisition, passage reading, and errors for three middle school students with intellectual disabilities. Journal of Developmental and Physical Disabilities, 23, 241-255. http://dx.doi.org/10.1007/s10882-010-9220-2

Scruggs, T. E., \& Mastropieri, M. A. (2001). How to summarize single-participant research: Ideas and applications. Exceptionality, 12, 227-244. http://dx.doi.org/10.1207/S15327035EX0904_5

Scruggs, T., \& Mastropieri, M. A. (2013). PND at 25: Past, present and future trends in summarizing single subject research. Remedial and Special Education, 34, 9-19. http://dx.doi.org/10.1177/0741932512440730

Scruggs, T., \& Mastropieri, M. A., \& Casto, G. (1987). Summarizing single case research: issues and applications. Behavior Modification, 22, 221-242. http://dx.doi.org/10.1177/01454455980223001

Shapiro, E. S. (2011). Academic skills problems: Direct assessment and intervention (4th ed.). New York, NY: Guilford Press.

Silbert, J., Carnine, D. W., \& Stein, M. (1981). Direct instruction mathematics. Columbus, OH: Charles E. Merrill.

Skarr, A., Zielinski, K., Ruwe, K., Sharp, H., Williams, R. L., \& McLaughlin, T. F. (2014). The effects of direct instruction flashcard and math racetrack procedures on mastery of basic multiplication facts by three elementary school students. Education and Treatment of Children, 37, 77-93. http://dx.doi.org/10.1353/etc.2014.0007

Steedly, K., Dragoo, K., Arefeh, S., \& Luke, S. (2008). Predicting math teacher's educational Beliefs about teaching students' with mathematical learning difficulties. Journal of Arts, Social Sciences, and Scientific Studies, 3, 13-23.

Stokes, T. F., \& Baer, D. M. (1977). An implicit technology of generalization. Journal of Applied Behavior Analysis, 10, 349-367. http://dx.doi.org/10.1901/jaba.1977.10-349

Stokes, T. F., \& Baer, D. M. (2003). Mediated generalization: An unfinished portrait. In K. S. Budd, \& T. F. Stokes (Eds.). A small matter of proof: The legacy of Donald M. Baer (pp. 125-138). Reno, NV: Context Press.

Swanson, H. L., Carson, C., \& Lee, C. (1996). A selective synthesis of intervention research for students with learning disabilities. School Psychology Review, 25, 370-390.

Swanson, H. L., Harris, K., \& Graham, S. (2013). Handbook of learning disabilities. New York, NY: Guilford Press.

Thomas, R., McLaughlin, T. F., \& Derby, K. M. (2015). Employing direct instruction flashcards to teach academic skills to students with high incidence disabilities: A review. International Journal of English and Education, 4(4), 404-421. Retrieved from http://www.ijee.org/current_issue

Treacy, R., McLaughlin, T. F., Derby, K. M., \& Schlettert, E. (2012). The effects of flashcards and student selected reinforcers with goals and additional practice with multiplication facts for two intermediate elementary students with behavior disorders. Academic Research International, 2(1), 469-476. Retrieved from http://174.36.46.112/ savaporg/journals/issue.htm/

Wallace, A. H., \& Gurganus, S. P. (2005). Teaching for mastery of multiplication. Teaching Children Mathematics, 8, 26-33. 
Zentell, S., \& Ferkis, M. A. (1993). Mathematical problem solving for youth with ADHD with and without learning disabilities. Learning Disability Quarterly, 16, 6-18. http://dx.doi.org/10.2307/1511156

\section{Copyrights}

Copyright for this article is retained by the author(s), with first publication rights granted to the journal.

This is an open-access article distributed under the terms and conditions of the Creative Commons Attribution license (http://creativecommons.org/licenses/by/3.0/). 